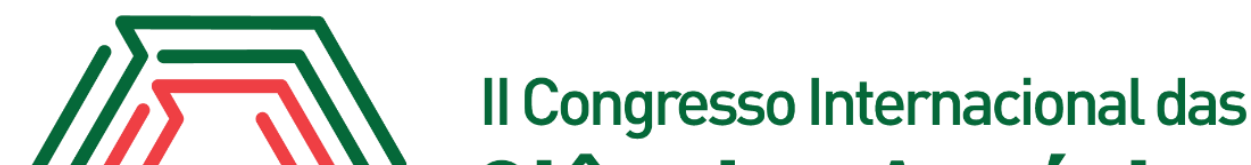 Ciências Agrárias COINTER - PDVAgro 2017
}

\section{PRÁTICAS AGROECOLÓGICAS NO VALE DO AÇU}

\author{
Apresentação: Relato de Experiência \\ Deise Lais da Silva Bento ${ }^{1}$; Júlio Justino de Araújo ${ }^{2}$
}

\section{Introdução}

A Agroecologia não se propõe como uma panacéia para resolver todos os problemas gerados pelas ações antrópicas de nossos modelos de produção e de consumo, nem espera ser a solução para as mazelas causadas pelas estruturas econômicas globalizadas e oligopolizadas, senão que busca, simplesmente, orientar estratégias de desenvolvimento rural mais sustentável e de transição para estilos de agriculturas mais sustentáveis, como uma contribuição para a vida das atuais e das futuras gerações neste planeta de recursos limitados, (CAPORAL, 2004).

Nesse contexto o NEA (Núcleo de Estudos em Agroecologia) tem um papel fundamental para o fortalecimento da Agricultura Familiar no Vale do Açu-RN através da identificação, resgate, validação, melhoramento, beneficiamento, conservação e intercâmbio de materiais genéticos de interesse para a Agroecologia por meio de metodologias participativas que promovem a construção e a socialização das práticas e conhecimentos e o acesso coletivo aos materiais trabalhados.

\section{Relato de Experiência}

O NEA (Núcleo de Estudos em Agroecologia), através da extensão, promove a troca de saberes entre professores, estudantes, técnicos, servidores e agricultores da região do Vale do AçuRN. É por meio da extensão que o estudante vivencia experiências únicas onde potencializa todo o seu aprendizado, se insere no contexto da agricultura familiar e reflete sobre práticas sustentáveis sendo assim um sujeito capaz de transformar o meio onde está inserido.

\footnotetext{
${ }^{1}$ Graduanda em Tecnologia em Agroecologia, Instituto Federal de educação, ciência e tecnologia do Rio Grande do Norte, deise.b@academico.ifrn.edu.br.

${ }^{2}$ Doutorado em manejo de solo e água, Universidade Federal Rural do Semi-árido (UFERSA), julio.araujo@ifrn.edu.br.
} 
O NEA (Núcleo de Estudos em Agroecologia) desenvolveu e continua desenvolvendo vários projetos com o intuito de fortalecer a agricultura familiar no vale do Açu/RN. O primeiro projeto foi a Implantação de unidades demonstrativas e caracterização sócio-ambiental para o fortalecimento da Agricultura Familiar no Vale do Açu-RN.

O segundo Projeto foi sementes crioulas para o fortalecimento da agricultura familiar do vale do açu - RN. As ações desses projetos trouxeram benefícios para toda comunidade, considerando que é fundamental pensar a viabilidade e o desenvolvimento da agricultura familiar não só do ponto de vista econômico, mas também social e ecológico, considerando o conjunto de necessidades que a família e o sistema de produção apresentam para garantir a qualidade e o modo de vida da população do campo.

Imagem 1: NEA presente I Feira de Agricultura Familiar e economia solidaria do Vale do Açu (FAFESVA). Fonte: Própria

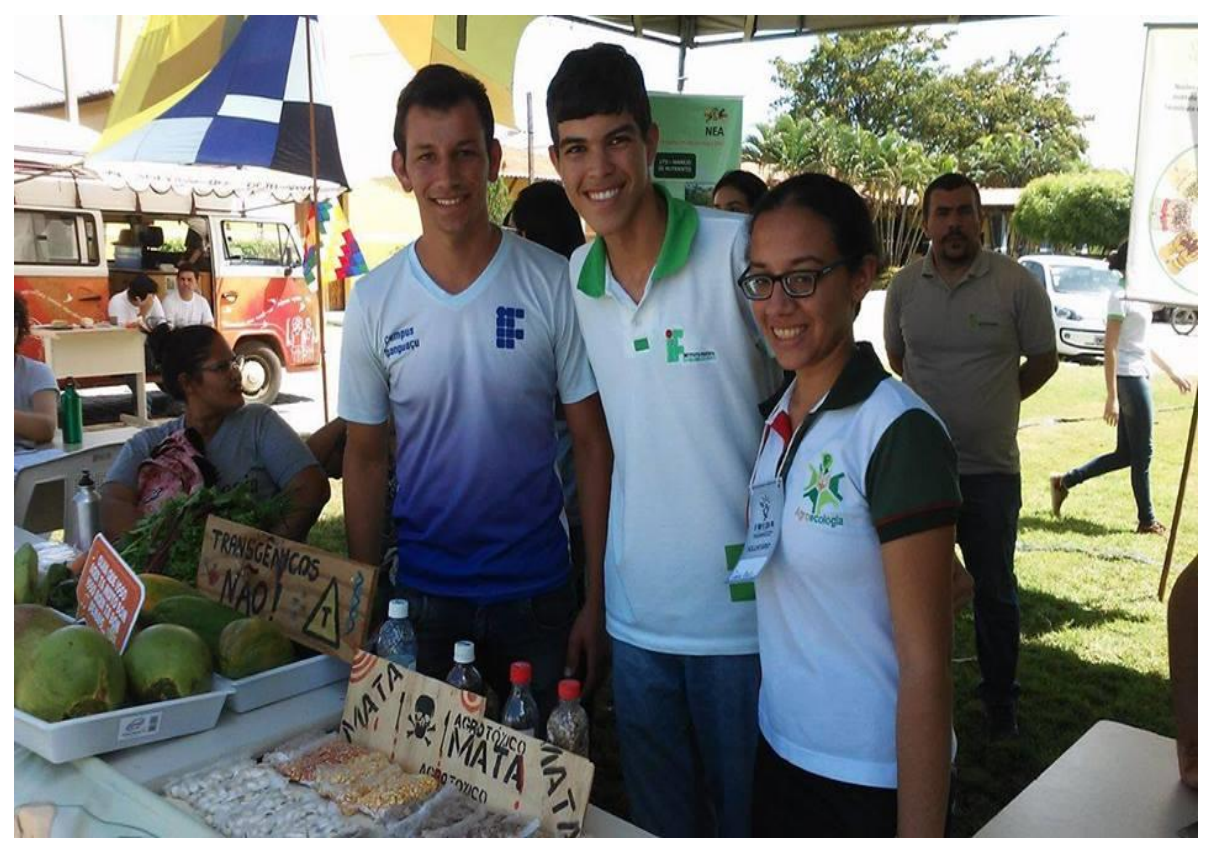

\section{Considerações}

Através das parcerias estabelecidas entre o Núcleo de Estudos em Agroecologia, o Instituto federal de Educação, Ciência e Tecnologia Rio Grande do Norte - Campus Ipanguaçu e os agricultores familiares da região do vale do açu, obteve-se o apoio necessário para o desenvolvimento de atividades visando contribuir com o fortalecimento da Agricultura Familiar no Vale do Açu-RN, a valorização do campo e dos saberes adquiridos pelos agricultores e agricultoras ao longo da sua jornada no meio rural, propostas através da implantação do Projeto. 
As ações do projeto de extensão, beneficiam os agricultores familiares, através do estímulo à busca de parcerias tanto das secretarias de agricultura como também das Assistência Técnica e Extensão Rural (ATER), também contribuem na realização de eventos que tem como foco o incentivo a agricultura familiar.

\section{Referências}

CAPORAL, Francisco Roberto. Agroecologia: alguns conceitos e princípios. Brasília: MDA/SAF/DATER-IICA, 2004. 